\title{
Characterization of Face Sheet/Core Debonding Strength in Sandwiched Medium Density Fiberboard
}

\author{
Mohamed K. Hassan \\ Production and Design Engineering Department, Faculty of Engineering, Minia University, Minia, Egypt \\ Email: mkorrany@msn.com
}

How to cite this paper: Hassan, M.K. (2017) Characterization of Face Sheet/Core Debonding Strength in Sandwiched Medium Density Fiberboard. Materials Sciences and Applications, 8, 673-684.

https://doi.org/10.4236/msa.2017.89048

Received: July 6, 2017

Accepted: August 22, 2017

Published: August 25, 2017

Copyright $\odot 2017$ by author and Scientific Research Publishing Inc. This work is licensed under the Creative Commons Attribution International License (CC BY 4.0).

http://creativecommons.org/licenses/by/4.0/

\section{(c) (i) Open Access}

\begin{abstract}
Medium density fiberboard (MDF) is a highly competitive wooden material especially in office furniture industry. Damage and failure occur frequently in MDF due to low mechanical properties. In the present work, a modification was performed to enhance fracture properties of MDF. The MDF plate/core was inserted into two layers (face sheet) of glass fiber composite laminates using hand layup technique. Face sheet/core delamination involves the separation of a face sheet from the core material in a sandwich MDF. Therefore, delamination test using double cantilever beam (DCB) specimen was carried out. The test measured the debonding fracture toughness $\left(\mathrm{G}_{\mathrm{IC}}\right)$ or separation strength between face sheet material (glass fiber/epoxy laminates) with MDF core material. The test is based on compliance strategy measuring fracture toughness $\left(\mathrm{G}_{\mathrm{IC}}\right)$. It was found that the fracture toughness was increased. Extended finite element model (XFEM) based on virtual crack closer technique (VCCT) was constructed to simulate the delamination behaviors of face sheet/core materials. The model results were in good agreement with the experimental ones.
\end{abstract}

\section{Keywords}

Double Cantilever Beam, Delamination, Face Sheet/Core,

Medium Density Fiberboard

\section{Introduction}

Medium density fiberboard (MDF) nowadays is the key material in furniture industry as a competitive wood panel product. It is a composite of sugarcane bagasse fibers, and urea-formaldehyde resin. Sugarcane bagasse particleboards 
were manufactured using a heated automatic press by Maloney [1]. Through thickness crack is commonly known as delamination failure in layered composite material. Delamination is a measure of debonding strength of two adhesive layers. Delamination is determined though mode I, mode II and Mode III fracture toughness [2].

Getting good estimation of delamination and interface problems has an important point of view in a lot of works [3] [4] [5]. Face sheet/core material is considered as a composite sandwiched material which depends on debonding of two materials having interfaces.

James G. Ratcliffe [6] used a single cantilever beam (SCB) specimen to standardize it for the purpose of measuring the critical strain energy release rate related to debonding process which can be considered a fracture toughness of material.

Maryam Sobhani et al. [7] studied mechanical and physical properties of face/ core structure manufactured from paulownia wood as core material and surfaces of laminate of glass fiber reinforced epoxy resin. The experimental results showed that a noticeable enhancement was achieved with the layer laminates respect to thickness. The resin gave good bond with the wood than polyester. The paulownia was concluded to be good for manufacturing sandwich pan or facesheet/core structure.

Abdellah et al. [8] numerically determined the critical strain release energy of carbon composite multilayer laminates using FEA. The results were in good agreement with the experimental one. The model was based on J-integral fracture technique.

Alsofie et al. [9] studied mechanical properties of facesheet/core material of medium density fiberboard as core material and multilayer glass fiber composite laminates as facesheet. There results were in good acceptable with the experimental data.

Hassan et al. [10] experimentally measured fracture toughness of sandwiched material of GLARE using both center edge notched and compact tension specimen. GLARE material is facesheet/core material which is consisted of aluminum thin sheet as facesheet material and glass fiber reinforced epoxy as core material.

Many works [11] [12] [13] [14] [15] studied the fracture and characteristic properties of facesheet/core material but there is lack of study focus on delamination in through thickness which corresponding to fracture toughness.

\section{The Novelty of the Present Research}

The novelty of the present work concentrated in the following:

- Measure debonding strength in glass fiber reinforced laminates/MDF sandwich interface as face sheet/core material through measuring fracture toughness. The measuring test was based on DCB specimen to standardize this test for such material.

- Extended Finite element model (XFEM) which is based on crack closure 
technique was used to establish XFEM with linear elastic fracture mechanics (LEFM) in facesheet/core material.

\section{Material and Characterizing}

The face sheet/core material is manufactured from woven glass fiber reinforced epoxy which, constituent material is listed in Table 1, as face sheet phase. Whereas, the core phase is commercial MDF plate of thickness $7 \mathrm{~mm}$. The MDF plate supplied dimension of $40 \times 80 \mathrm{~cm} \times 0.7 \mathrm{~cm}$.

\section{Methodology}

The used methodology in the present paper was first, manufacturing the work specimen using hand layup technique, followed by the DCB test and data reduction. Then, X-FEM based on VCCT to simulate DCB. Finally, test results were presented and prediction of fracture toughness was carried out.

\subsection{Hand Layup Technique}

The face sheet/core plate is produced using a hand layup technique [16] [17] (see Figure 1(a)). The hand layup technique was considered suitable and cheaper than other composite manufactured technique [17] [18].

The technique can be summarized as follows:

1) A mold consists of two glass plates; the surfaces of one of this two glass plates were treated with release agent (wax). The composite laminates of two layers were spread over this surface of glass plate then the MDF plate of $7 \mathrm{~mm}$ was placed over with the adhesive epoxy resin was spread over. Another two layers of glass fiber composite laminates were placed over MDF plate. Note that at nearly $70 \mathrm{~mm}$ from the edge of MDF before the glass fiber composite laminates layers were placed an inserts of $0.5 \mathrm{~mm}$ thin non-sticking aluminum film to create the restart crack length of DCB test specimen. Then a glass plate was placed on the cellophane paper, and equal weights were distributed on the glass plate to obtain an almost constant thickness for the composite laminate (see Figure 1(b)).

2) The curing process achieved in room temperature for 21 days. After curing margins of nearly $10 \mathrm{~mm}$ were cut from the produced plate edges [17]. The fiber

Table 1. Mechanical and physical properties of E-glass fiber and epoxy resin [20] [21].

\begin{tabular}{ccccc}
\hline Properties & E-glass & Kemapoxy (150 RGL) & MDF & Laminates \\
\hline Density $\left(\mathrm{kg} / \mathrm{m}^{3}\right)$ & 2540 & $107 \pm 2$ & $500^{\circ}-1000$ & \\
Tensile strength (MPa) & 2000 & $50-100$ & 6.2 & 220 \\
young modulus (GPa) & 76 & $1.2-4.5$ & $450(\mathrm{MPa})$ & 200 \\
Passion ratio & 0.25 & 0.35 & 0.3 & 0.3 \\
In plane shear modulus & 30.8 & 1.24 & $-\cdots--$ & $-\cdots$ \\
Failure strain & ----- & 1.7 & $-\cdots--$ \\
\hline
\end{tabular}




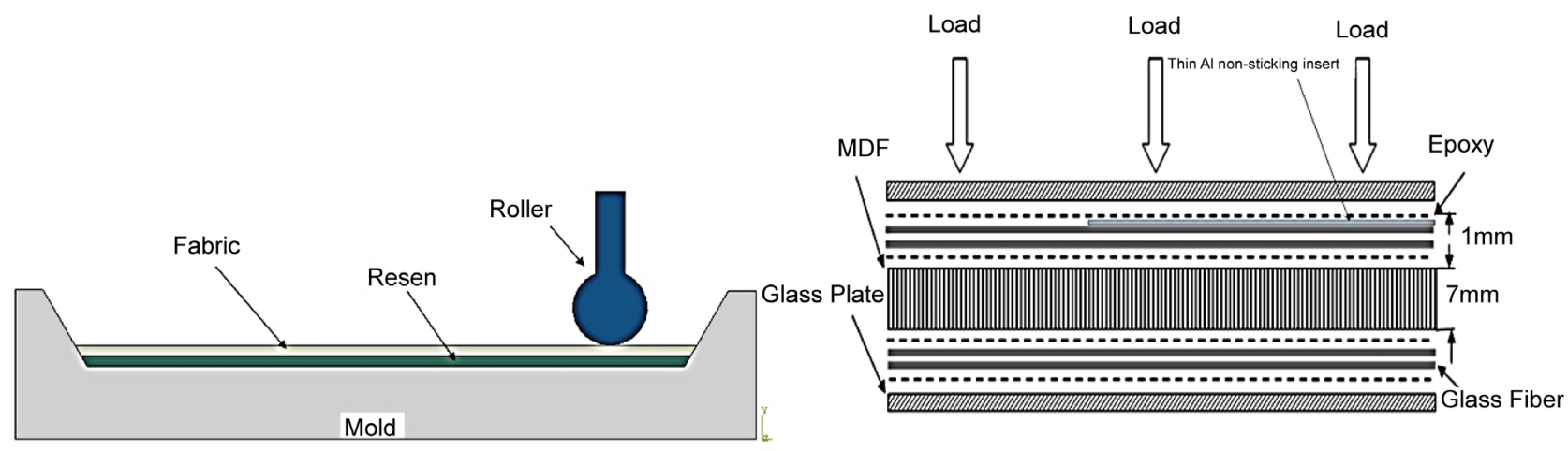

(a)

(b)

Figure 1. Manufacturing face sheet/core (a) Hand layup technique; (b) Specimen sandwich technique layout.

volume fraction $\mathrm{Vf}$ was determined using the ignition burnet removal technique according to ASTM D3171-99 standard [19]. The volume fraction Vf was determined as $8 \%$. The produced composite specimen of sandwiched MDF has a thickness of $9 \mathrm{~mm}$.

\subsection{Delamination Test}

Double Cantilever Beam (DCB) is a common type specimen in mode I tests to measured delamination, schematically illustrated in (Figure 2 [22]). Thin nonsticking aluminum film was inserted between facesheet/core interfaced acts as starter crack. Tensile load is applied to let starter crack propagates through specimen thickness ( $t$ ) via two piano hinge at cross head speed $2 \mathrm{~mm} / \mathrm{min}$ of universal testing machine. Visual observation for delamination lengths during the test is acceptable [2].

The data reduction is based on experimental compliance calibration and on beam theory [2]. Scale marked in $1 \mathrm{~mm}$ increments on one end of the DCB face starting from the tip of the insert to a length of $60 \mathrm{~mm}$ to simplified observation of crack length propagation. The observation is made at every $1 \mathrm{~mm}$ of growth for the first $15 \mathrm{~mm}$, and then at every $5 \mathrm{~mm}$ of growth for reminder of test. The specimen dimensions are; thickness of (t) $1 \mathrm{~mm}$, width (B) $50 \mathrm{~mm}$ starter length (ao) $50 \mathrm{~mm}$ and specimen length is $200 \mathrm{~mm}$. Displacement-controlled static tests are conducted according to ASTM Standard D5528 [23].

\subsection{Data Reduction}

According to Modified Beam Theory (MBT) method [22] the fracture toughness can be measured as follows:

$$
G_{I c}=\frac{3 P \delta}{2 B(a+|\Delta|)}
$$

where $P$ is the load, $\boldsymbol{\delta}$ is the displacement, B is the specimen width, a is the initial delamination length, and $\Delta$ is the delamination length correction factor. The compliance related to delamination length with the following Equation [2] [22]. 


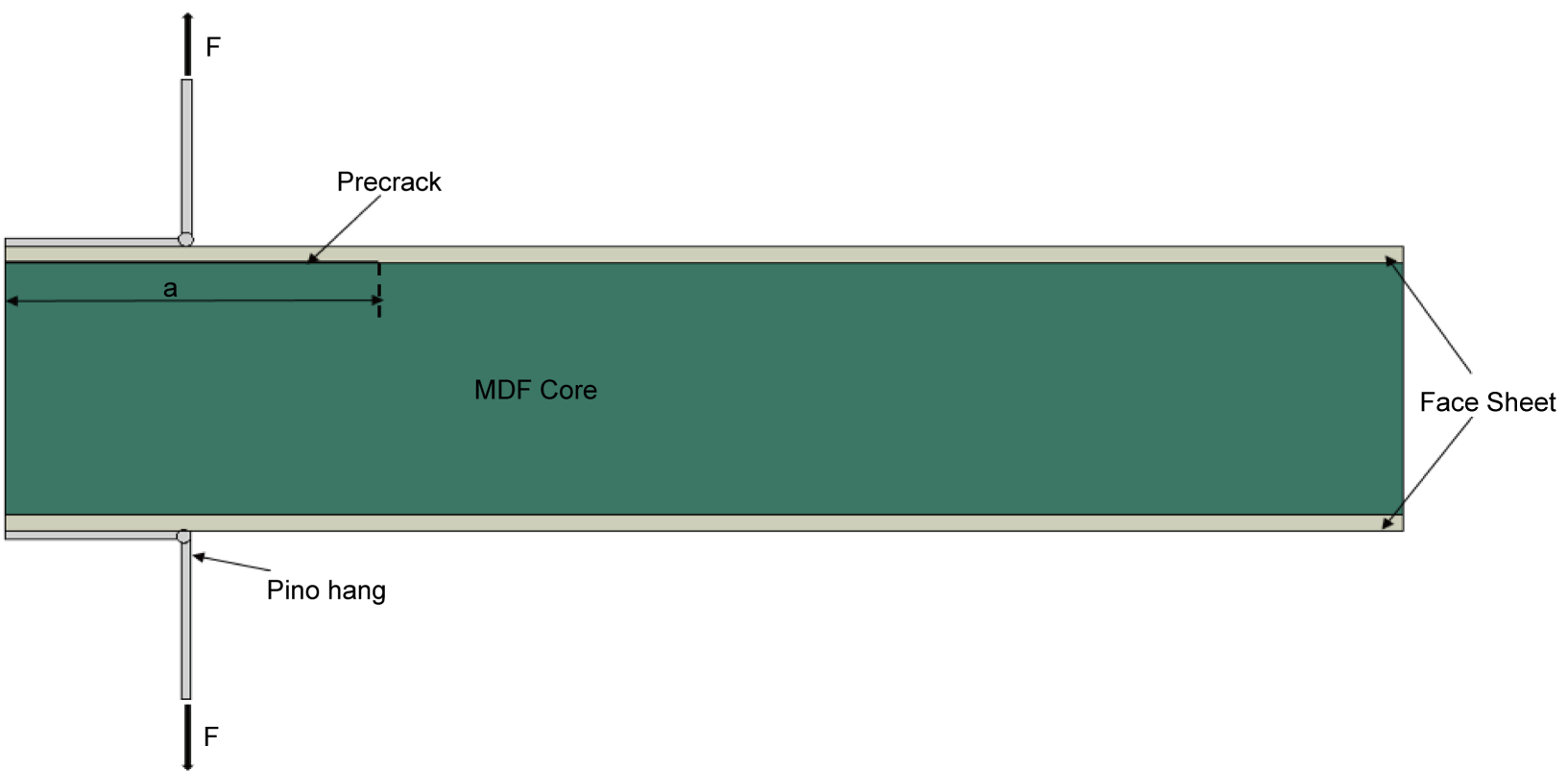

Figure 2. Schematic drawing for DCB test specimen of glass fiber laminates/MDF composite sandwich.

$$
C^{1 / 3}=m(a+|\Delta|)
$$

The constants $\mathrm{m}$ and $\Delta$ are determined by a least squares line fit to a plot of the observed delamination lengths (a) from the static test versus the cube root of the corresponding compliance $\mathrm{C}$.

\subsection{X-FEM Based VCCT}

Belytschko and Black [23] had developed the Extended Finite Element Method (X-FEM). This method used basically the concepts of partition of finite element unity and enrichment function [24]. The main advantage of X-FEM that mesh does not need to related to the geometry anymore. Therefore, remeshing and refinement are not urgent, and failure analysis of crack is established in numerical accuracy around the crack tip. More descriptions are found in [25] [26].

XFEM is newly associated with Virtual Crack Closure Technique (VCCT) based in LEFM criteria applicable for ductile fracture like matrix cracking in interfaced debonding problems like facesheet/core materials. Mesh arrangement or refinement are not required in VCCT. VCCT is limited which can only implemented with linear elastic fracture mechanics cases [27]. The crack closure method is based on Irwin's crack closure integral [28] [29]. The method is based on the assumption that the energy $\Delta \boldsymbol{E}$ released when the crack is extended by $\Delta \boldsymbol{a}$ from a to $\boldsymbol{a}+\Delta \boldsymbol{a}$ is identical to the energy required to close the crack faces Figure 3(a). For a crack modeled with two-dimensional four-node elements as shown in Figure 3 the $\Delta \boldsymbol{E}$ required to close the crack along one element side can be calculated as [27] [30]:

$$
\Delta E=\frac{1}{2} F \delta
$$




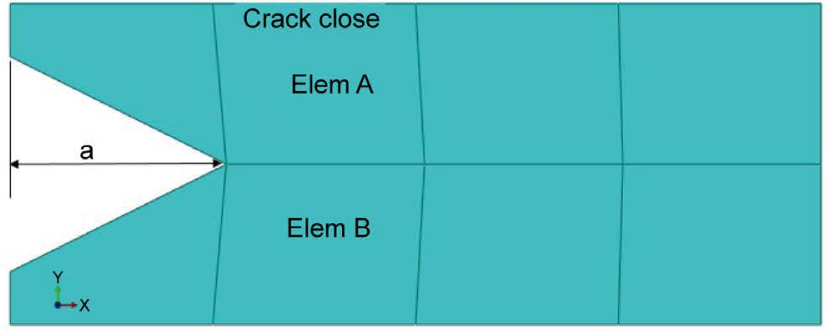

(a)

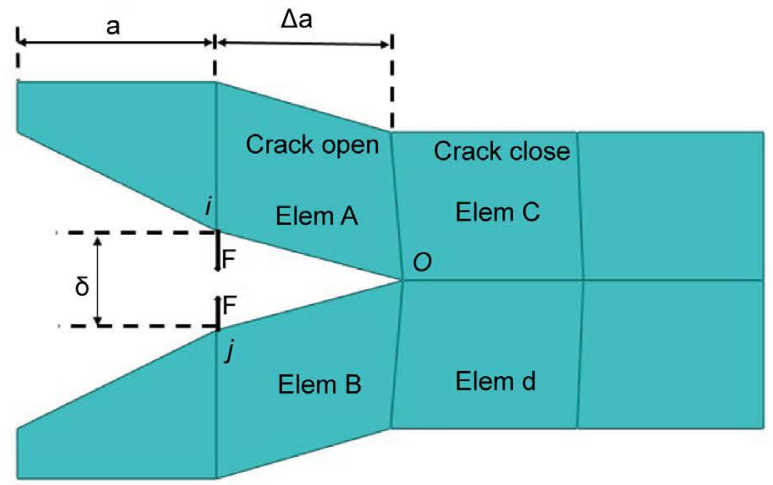

(b)

Figure 3. Crack closure principal.

where $\mathrm{F}$ is the applied force needed to bond nodes $\boldsymbol{i}$ and $\boldsymbol{j}$ and $\boldsymbol{\delta}$ is the maximum crack opening displacement which is the normal distant between node $\boldsymbol{i}$ and $\boldsymbol{j}$ (see Figure 3(b)). To make crack growth and advance the load $\mathrm{F}$ should equal the internal cohesive at point (o). Therefore, it can be calculated the surfaces release energy $\mathrm{G}$ and stress intensity $\mathrm{K}$.

The evaluated damage for traction-separation laws is based on critical surface release energy of $11.7 \mathrm{~J} / \mathrm{mm}^{2}$. The maximum principal stress is the value of MDF nominal strength and it is measure using simple tension test. In addition, the elastic young's modulus is measured from stress strain curves which are listed in Table 1. In the X-FEM based on VCCT the bilinear softening of power low of 2 is used with normal direction to the crack and the 3 modes of fracture surface energies of $11.7 \mathrm{~J} / \mathrm{mm}^{2}$. The assumed softening function has great effect in the accuracy of simulation as cited in [26].

The surface input line for VCCT is as follows:

- Surface Behavior

- Fracture Criterion, type $=$ VCCT, mixed mode behavior $=\mathrm{BK}$, normal direction $=1$, tolerance $=3.5$

$0.0117,0.0117,0.0117, \quad 2$.

\subsection{Finite Element Domain, Mesh and Boundary Condition}

The swept meshing technique is used to generate a domain of 38650 elements, and 2288 for core material and Facesheet glass fiber plate respectively. The (C3D8R) element type is used, as it is shown in Figure 4(a).

The specimen domain is attached to the testing set up where load is applied to the two-piano hinge vertically. The displacement control boundary conditions technique is applied as it is shown in Figure 4(b).

The interaction between the facesheet/core interfaces is assumed to be constrained as (tie) Figure 5(a), while the interaction cracks face and specimen domain is applied as X-FEM based VCCT, the domain with interaction is shown in Figure 5(b).

For propose of mesh objectivity and convergence the work in [26] had con- 


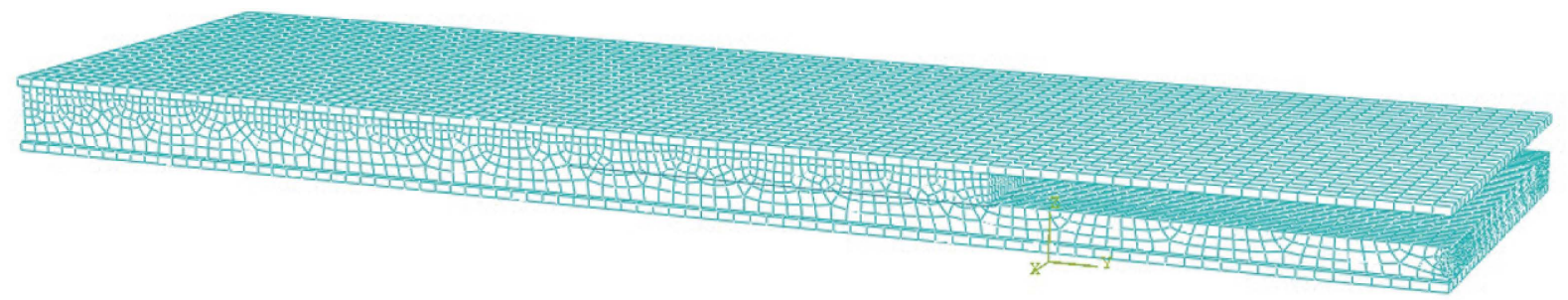

(a) Mesh Domain

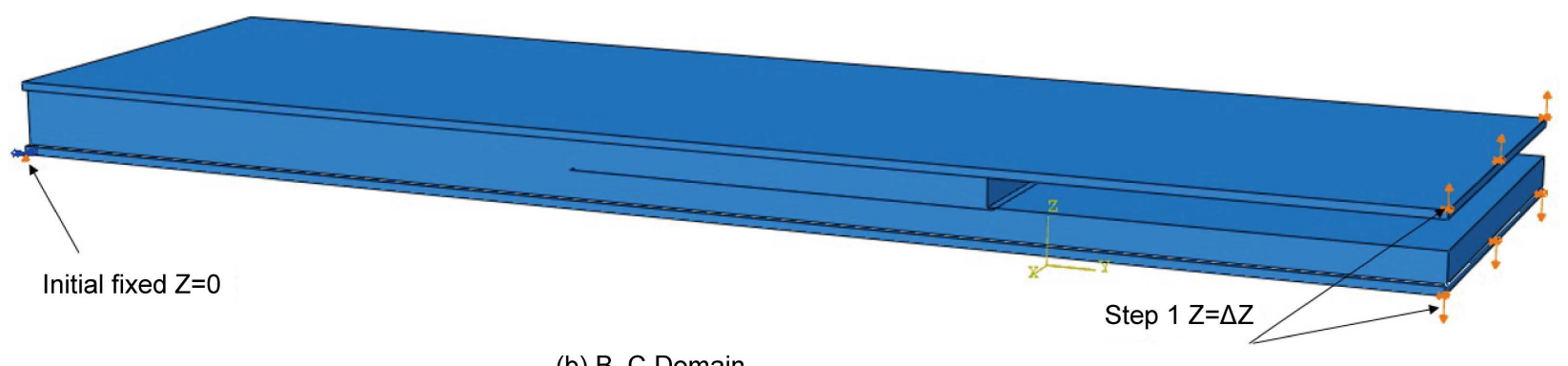

(b) B. C Domain

Figure 4. X-FEM domain. (a) Mesh domain; (b) Boundary condition domain.

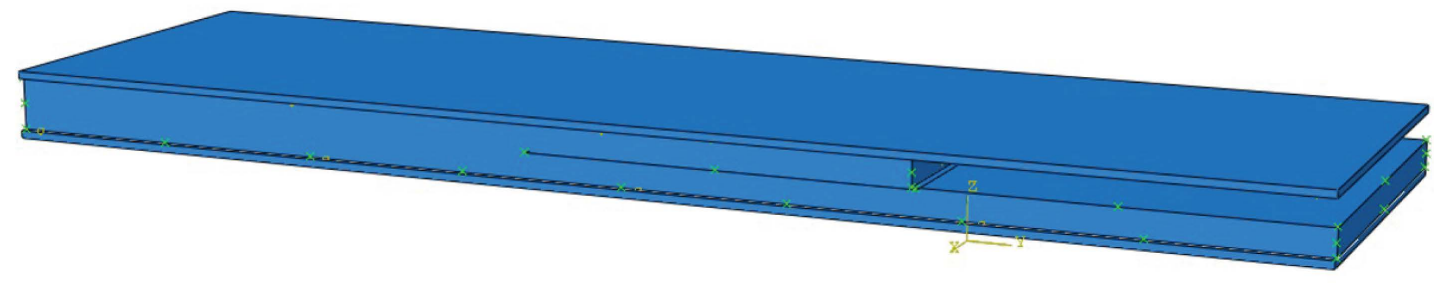

(a) X-FEM based VCCT

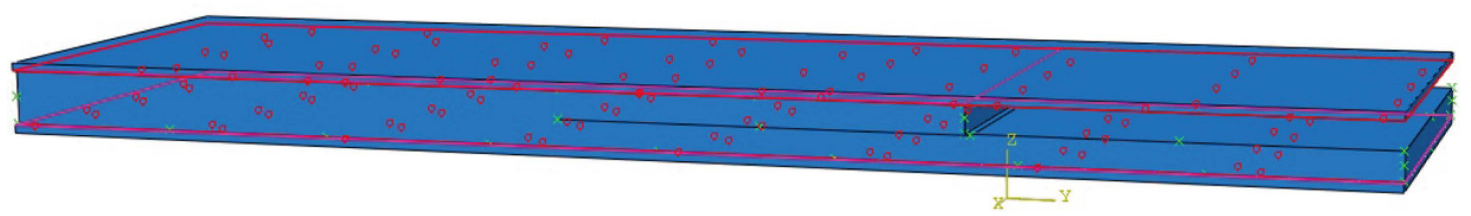

(b) Facesheet/core interface

Figure 5. X-FEM interaction. (a) X-FEM based VCCT; (b) Facesheet/core interface.

firmed that the solution is independent of the mesh density refinement.

\section{Result and Discussion}

Figure 6(a) shows load displacement curve with compliance at each crack length visually observed on the scale which is drawing on the DCB face. Compliance for each crack extension is measured experimentally as the inverse slop of the linear line as it illustrates in Figure 6(b). The compliance is calculated as [31]: 


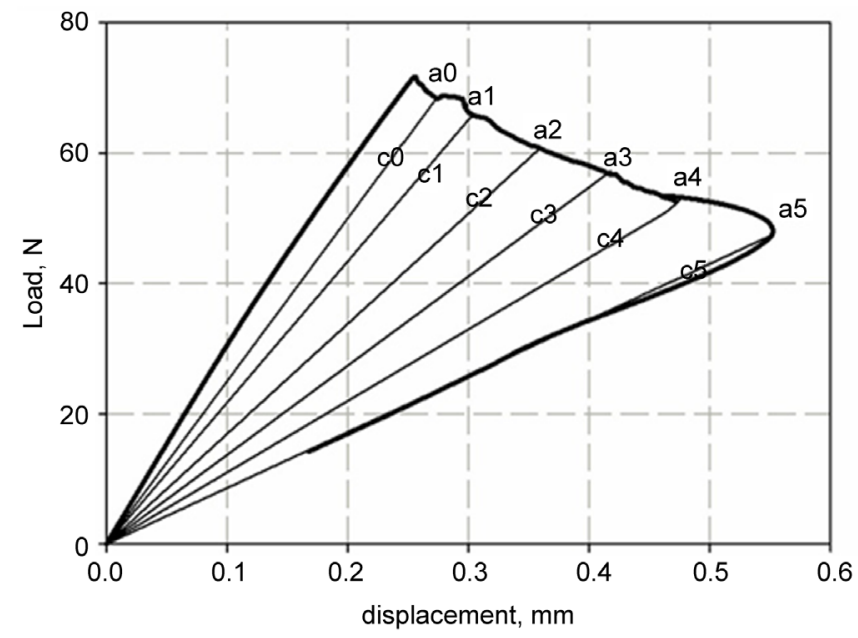

(a)

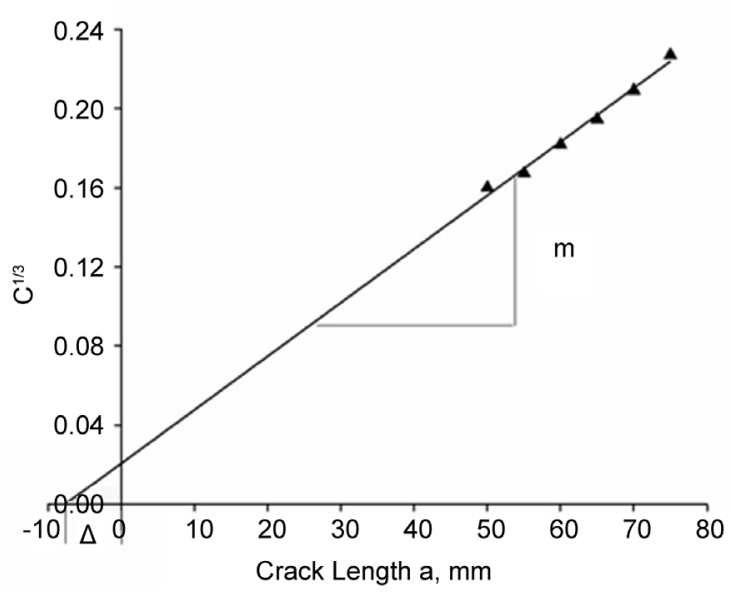

(b)

Figure 6. DCB test. (a) Load displacement curve; (b) Compliance parameters, $\mathrm{m}$ and $\Delta$.

$$
C=\frac{U}{P}
$$

where $u$ is load displacement, $P$ applied load.

Each data for all the cube root of the corresponding compliance (C) are plotted verses crack length a (see Figure 7(a)). Parameters of Equation (2) can be then measured as 0.0027 for $\mathrm{m}$ and -7.2 for $\Delta$. By substituent these parameters in Equation (1), the fracture toughness can be calculated as 11.7 $\mathrm{J} / \mathrm{m}^{2}$ at maximum load $\mathrm{P}$ and corresponding displacement $\delta$. The value of fracture toughness is low as the delamination occurs through core material MDF not at facesheet/core interface; this is clearly shown in Figure 8. The deboning between layers of composite laminates and MDF is very good therefore, modes of failure is opening mode (see Figure 7(a)). The delamination through MDF plates clearly appears because the upper and lower layers of the glass fiber reinforced epoxy laminates are deeply diffused MDF plate thickness. The low strength of MDF material returns to presence of medulla in sugarcane bagasse [32].

The sugarcane bagasse fiber braking matrix cracking is shown in Figure 7 (b). Strength distribution for through thickness deboning decreases from outer surface to the depth of the inner thickness surface. The predicted Jintegral of fracture is shown in Figure 9, and give value equal to nearly 12 $\left(\mathrm{J} / \mathrm{m}^{2}\right)$. This value is much closed to the measured one. The fracture mode is similar to that of XFE-VCCT obtained as it is illustrated in PHILSM and STATUSXFEM image of XFEM Figure 9(a), Figure 9(b).

\section{Conclusion}

The coating process performed on commercial MDF is achieved with help of glass fiber reinforced epoxy. The fracture toughness of debonding strength at glass fiber reinforced epoxy resin laminates/MDF core interfaced is stronger 


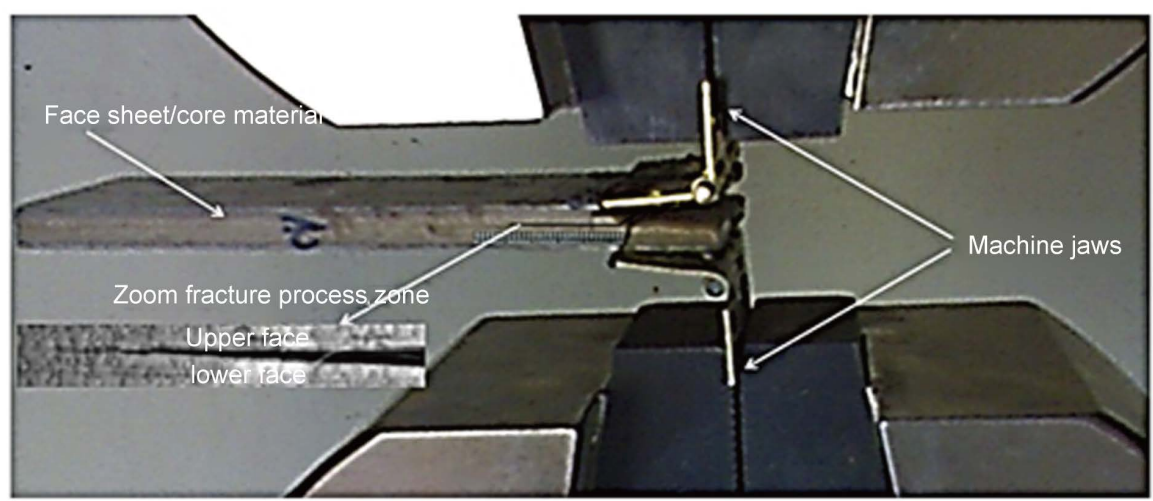

(a)

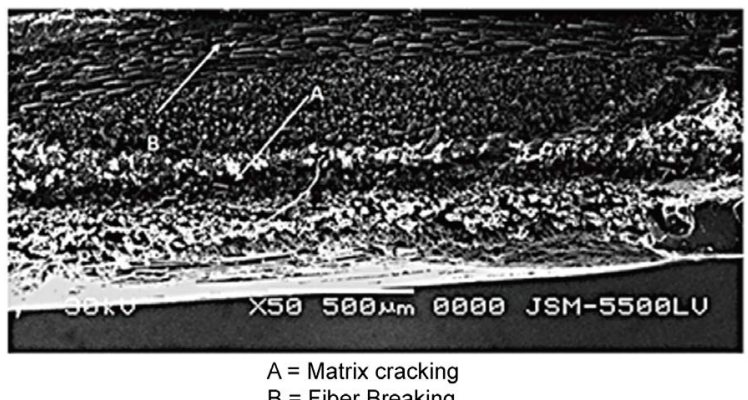

(b)

Figure 7. Delamination test set up. (a) Through thickness crack; (b) SEM analysis of fracture face.

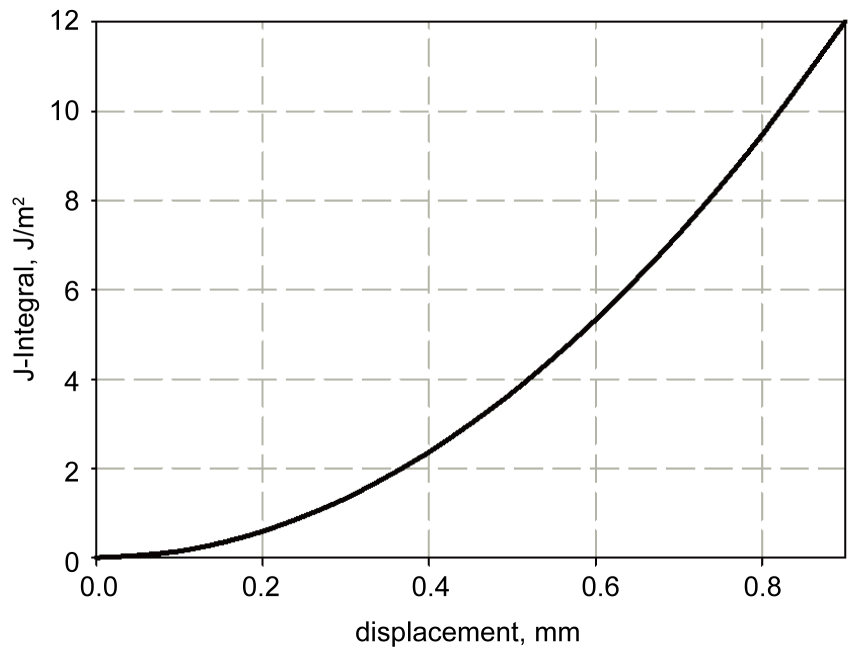

Figure 8. Predicted J-integral of mode I fracture.

than the debonding of core material itself based on urea formaldehyde resin. These results come from that delamination is created through MDF center. Therefore, the modified MDF as wood material based on facesheet/core technique is good for increasing MDF field of applications not in furniture only. The X-FE analysis based on VCCT is considered new and acceptable for prediction and simulation of delamination for facesheet/core material with the 

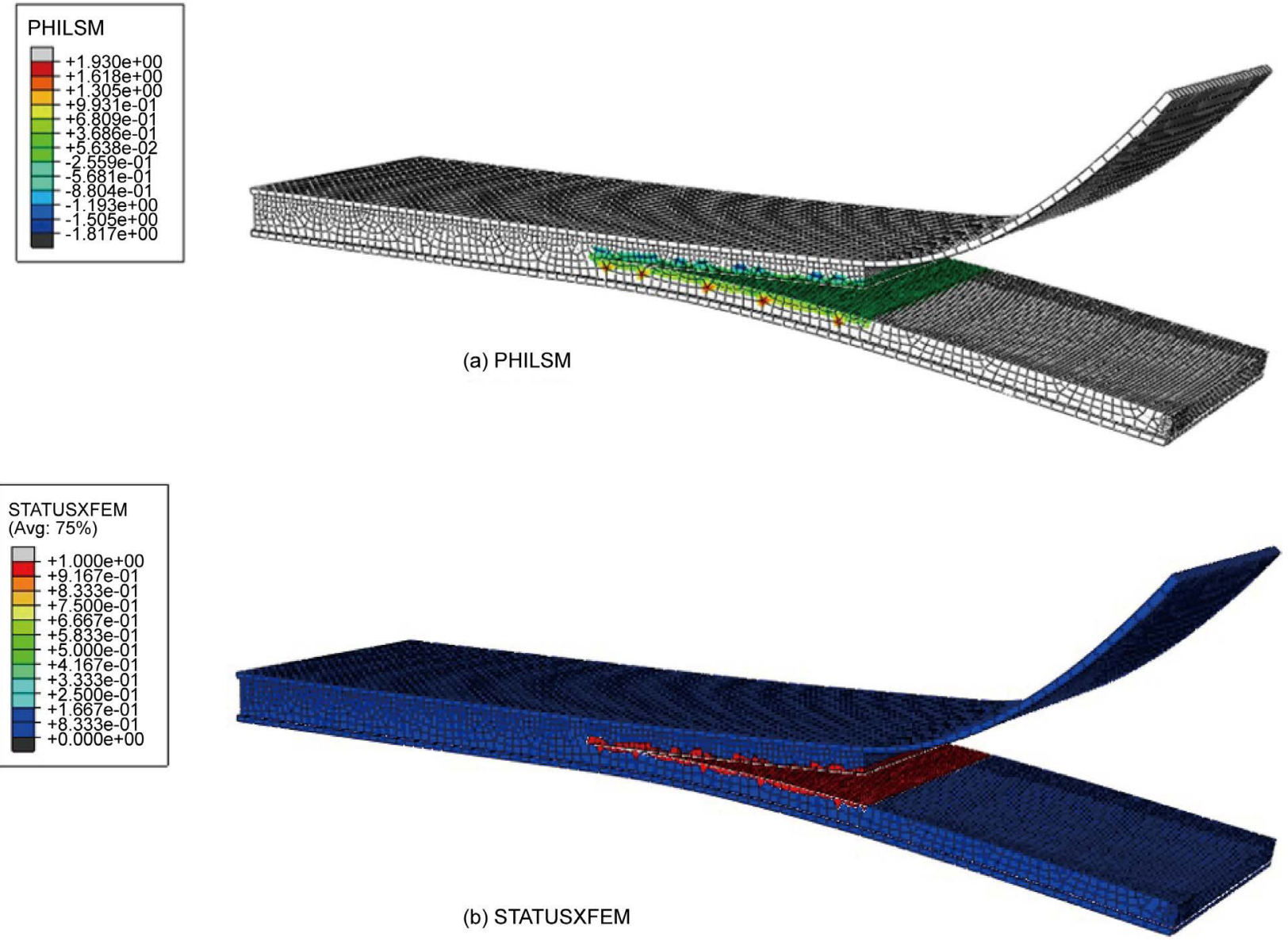

Figure 9. X-FEM contour. (a) PHILSM; (b) STATUSXFEM.

help of LEFM and cohesive zone parameters. These results established that polymer epoxies material give good compatibility with both glass fiber and MDF. The modified sandwiched technique for MDF as Facesheet/core material is confirmed to be good compatible and increasing bonds.

\section{References}

[1] Maloney, T. (1996) The Family of Wood Composite Materials. Forest Products Journal, 46, 18.

[2] Murri, G.B. (2014) Effect of Data Reduction and Fiber-Bridging on Mode I Delamination Characterization of Unidirectional Composites. Journal of Composite Materials, 48, 2413-2424. https://doi.org/10.1177/0021998313498791

[3] Comninou, M. (1990) An Overview of Interface Cracks. Engineering Fracture Mechanics, 37, 197-208. https://doi.org/10.1016/0013-7944(90)90343-F

[4] La Saponara, V., Muliana, H., Haj-Ali, R. and Kardomateas, G.A. (2002) Experimental and Numerical Analysis of Delamination Growth in Double Cantilever Laminated Beams. Engineering Fracture Mechanics, 69, 687-699. https://doi.org/10.1016/S0013-7944(01)00106-0

[5] Suo, Z. (1990) Singularities, Interfaces and Cracks in Dissimilar Anisotropic Media. Proceedings of the Royal Society of London A: Mathematical, Physical and Engineering Sciences, 427, 331-358. https://doi.org/10.1098/rspa.1990.0016 
[6] Ratcliffe, J.G. and Reeder, J.R. (2011) Sizing a Single Cantilever Beam Specimen for Characterizing Facesheet-Core Debonding in Sandwich Structure. Journal of Composite Materials, 45, 2669-2684. https://doi.org/10.1177/0021998311401116

[7] Sobhani, M., Khazaeian, A., Tabarsa, T. and Shakeri, A. (2011) Evaluation of Physical and Mechanical Properties of Paulownia Wood Core and Fiberglass Surfaces Sandwich Panel. Key Engineering Materials, 471-472, 85-90. https://doi.org/10.4028/www.scientific.net/KEM.471-472.85

[8] Mohammed, Y., Mohamed, K. and Hashem, A. (2010) Finite Element Computational Approach of Fracture Toughness in Composite Compact-Tension Specimens. International Journal of Mechanical and Mechatronics Engineering, 12, 57-61.

[9] Alsoufi, M.S., Abdellah, M.Y., Abdel-Jaber, G., Fahmy, H.S. and Hashem, A. (2015) Finite Element Simulation of Mechanical Behaviour of Sandwiched Medium Density Fibre Board. American Journal of Science and Technology, 2, 86-91.

[10] Hassan, M.K., Abdellah, M.Y., Azabi, S.K. and Marzouk, W. (2015) Fracture Toughness of a Novel GLARE Composite Material. International Journal of Engineering \& Technology, 15, 36-41.

[11] Hassan, M.K., Abdellah, M.Y., Azabi, S. and Marzouk, W. (2015) Investigation of the Mechanical Behavior of Novel Fiber Metal Laminates. International Journal of Mechanical \& Mechatronics Engineering IJMME-IJENS, 15, 112-118.

[12] Fotsing, E., Leclerc, C., Sola, M., Ross, A. and Ruiz, E. (2016) Mechanical Properties of Composite Sandwich Structures with Core or Face Sheet Discontinuities. Composites Part B: Engineering, 88, 229-239. https://doi.org/10.1016/j.compositesb.2015.10.037

[13] Thorsson, S.I., Xie, J., Marek, J. and Waas, A.M. (2016) Matrix Crack Interacting with a Delamination in an Impacted Sandwich Composite Beam. Engineering Fracture Mechanics, 163, 476-486. https://doi.org/10.1016/j.engfracmech.2016.04.003

[14] Oliveira, S.L., Mendes, R.F., Mendes, L.M. and Freire, T.P. (2016) Particleboard Panels Made from Sugarcane Bagasse: Characterization for Use in the Furniture Industry. Materials Research, 19, 914-922. https://doi.org/10.1590/1980-5373-MR-2015-0211

[15] Fiorelli, J., Sartori, D.D.L., Cravo, J.C.M., Junior, H.S., Rossignolo, J.A., Nascimento, M.F.D., et al. (2013) Sugarcane Bagasse and Castor Oil Polyurethane AdhesiveBased Particulate Composite. Materials Research, 16, 439-446. https://doi.org/10.1590/S1516-14392013005000004

[16] Khashaba, U., Sallam, H., Al-Shorbagy, A. and Seif, M. (2006) Effect of Washer Size and Tightening Torque on the Performance of Bolted Joints in Composite Structures. Composite Structures, 73, 310-317. https://doi.org/10.1016/j.compstruct.2005.02.004

[17] Mazumdar, S. (2001) Composites Manufacturing: Materials, Product, and Process Engineering. CRC Press, Boca Raton. https://doi.org/10.1201/9781420041989

[18] Mohammed, H.S.F., Abdellah, Y., Abdel-Jaber, G.T. and Hashem, A.M. (2017) Characteristic Properties of Glass Fiber Reinforced Sugarcane Bagasse Medium Density Fiber Board. Ciência \& Tecnologia dos Materiais, 29, No. 2.

[19] A. D3171-99 (1999) Standard Test Methods for Constituent Content of Composite Materials. ASTM International, West Conshohocken.

[20] Jones, R.M. (1998) Mechanics of Composite Materials. CRC Press, Boca Raton.

[21] Mallick, P.K. (2007) Fiber-Reinforced Composites: Materials, Manufacturing, and 
Design. CRC Press, Boca Raton. https://doi.org/10.1201/9781420005981

[22] Martin, R.H. and Murri, G.B. (1990) Characterization of Mode I and Mode II Delamination Growth and Thresholds in AS4/PEEK Composites. In: Garbo, S.P., Ed., Composite Materials: Testing and Design (Ninth Volume), ASTM International, West Conshohocken.

[23] Belytschko, T. and Black, T. (1999) Elastic Crack Growth in Finite Elements with Minimal Remeshing. International Journal for Numerical Methods in Engineering, 45, 601-620. https://doi.org/10.1002/(SICI)1097-0207(19990620)45:5<601::AID-NME598>3.0.CO;2-S

[24] Melenk, J.M. and Babuška, I. (1996) The Partition of Unity Finite Element Method: Basic Theory and Applications. Computer Methods in Applied Mechanics and Engineering, 139, 289-314. https://doi.org/10.1016/S0045-7825(96)01087-0

[25] Abaqus, A.V. (2009) 6.9 Documentation. Dassault Systemes Simulia Corporation, Providence.

[26] Abdellah, M.Y., Alsoufi, M.S., Hassan, M.K., Ghulman, H.A. and Mohamed, A.F. (2015) Extended Finite Element Numerical Analysis of Scale Effect in Notched Glass Fiber Reinforced Epoxy Composite/Rozszerzona Analiza Numeryczna Metoda Elementów Skonczonych Efektu Skali W Epoksydowym Kompozycie Z Karbem Wzmocnionym Włóknem Szklanym. Archive of Mechanical Engineering, 62, 217 236. https://doi.org/10.1515/meceng-2015-0013

[27] Leski, A. (2007) Implementation of the Virtual Crack Closure Technique in Engineering FE Calculations. Finite Elements in Analysis and Design, 43, 261-268. https://doi.org/10.1016/j.finel.2006.10.004

[28] Broek, D. (2012) Elementary Engineering Fracture Mechanics. Springer Science \& Business Media, Berlin.

[29] Flugge, I.G.R. (1958) Fracture. In: Flugge, V.I., Ed., Handbuch der Physik, Springer Verlag, Berlin, 558-590.

[30] Krueger, R. (2004) Virtual Crack Closure Technique: History, Approach, and Applications. Applied Mechanics Reviews, 57, 109-143. https://doi.org/10.1115/1.1595677

[31] Wang, C.H. (1996) Introduction to Fracture Mechanics. DSTO Aeronautical and Maritime Research Laboratory, Melbourne.

[32] Mendes, R.F., Mendes, L.M., Júnior, J.B.G., Santos, R.C.D. and Bufalino, L. (2009) The Adhesive Effect on the Properties of Particleboards Made from Sugar Cane Bagasse Generated in the Distiller. Revista de Ciências Agrárias, 32, 209-218. 
Submit or recommend next manuscript to SCIRP and we will provide best service for you:

Accepting pre-submission inquiries through Email, Facebook, LinkedIn, Twitter, etc. A wide selection of journals (inclusive of 9 subjects, more than 200 journals)

Providing 24-hour high-quality service

User-friendly online submission system

Fair and swift peer-review system

Efficient typesetting and proofreading procedure

Display of the result of downloads and visits, as well as the number of cited articles Maximum dissemination of your research work

Submit your manuscript at: http://papersubmission.scirp.org/

Or contact msa@scirp.org 